\title{
Analysis of Meshing Performance and Fatigue Reliability of Main Reducer Transmission Device for Rail Conveyor
}

\author{
Wenzhi Liu, Tianxiang Wang*, and Jian Tao \\ Institute of Mechanical Engineering, Inner Mongolia University of Technology, Hohhot, 010051, China
}

\begin{abstract}
Aiming at the reduction gear transmission of a rail conveyor, the two-stage main gear transmission system is taken as an example to establish the contact collision dynamics calculation model of the meshing gear teeth. The contact force of each gear speed and the tooth flanks of a gear with different helix angles in one motion cycle are calculated and analyzed. Based on the kinetic calculation results, the finite element calculation model of gear transmission friction contact is established. The Lagrangian multiplier method is used to calculate and analyze the meshing performance of the teeth under different helix angle contact conditions during one motion cycle. In order to avoid the contact fatigue of the gear teeth, the dangerous position of the tooth surface contact fatigue is obtained by finite element calculation. Based on the miner linear cumulative damage theory, the contact fatigue damage degree of the tooth surface of the tooth is obtained under different helix angle contact conditions.
\end{abstract}

Keywords: gear reducer; dynamic analysis; contact stress; fatigue damage

(Submitted on March 27, 2019; Revised on April 23, 2019; Accepted on June 20, 2019)

(c) 2019 Totem Publisher, Inc. All rights reserved.

\section{Introduction}

In the reduction gear transmission of a kind of rail conveyor, the main transmission device is a gear transmission system. The tooth surface contact force and the gear fatigue damage of the soft tooth surface gear during the meshing and rotating process are important indexes for measuring the meshing transmission performance of the reduction gear transmission. The transient contact force distribution between the gears and the fatigue damage measurements are difficult to assess during movement.

In order to grasp the meshing performance of the gear transmission process, the main gear transmission system of a rail conveyor deceleration device is taken as an example when different helix angles are used. To simulate actual working conditions, the virtual prototype software ADAMS and finite element calculation software are used. ANSYS Workbench establishes the contact collision dynamics calculation model and the friction contact finite element calculation model of the gear transmission. It also calculates and analyzes the motion, dynamic characteristics, and contact strength of the first-stage gear transmission in one motion cycle. Using NcodeDesignlife software and miner linear cumulative damage theory, the fatigue damage position and damage degree of the tooth surface under different helix angle contact states are evaluated, aiming at meshing transmission performance prediction before product formation.

\section{Dynamic Calculation of Main Transmission System}

\subsection{Dynamic Calculation Model}

The reduction gear of a track conveyor, which is the main transmission system, is designed as an involute cylindrical gear transmission, and the partial geometric parameters are shown in Table 1.

\footnotetext{
* Corresponding author.

E-mail address: $1298133361 @$ qq.com
} 
Table 1. Partial geometric parameters of main drive system

\begin{tabular}{|c|c|c|c|c|c|}
\hline & & Modulus $(\mathrm{m})$ & Number of teeth & Tooth width $(\mathrm{B})$ & Pressure angle $\left(\alpha_{n}\right)$ \\
\hline \multirow{2}{*}{ I level } & Big gear & 3 & 84 & 55 & 20 \\
\cline { 2 - 6 } & Small gear & 3 & 21 & 60 & 20 \\
\hline \multirow{2}{*}{ II level } & Big gear & 4 & 108 & 125 & 20 \\
\cline { 2 - 6 } & Small gear & 4 & 97 & 130 & 20 \\
\hline
\end{tabular}

During the gear meshing rotation, the contact of the gear and the slight fluctuation of the rotational speed cause collisions between the gears. Let The distance between the two contact tooth faces be $X$, ignoring the elastic deformation of the gear and the installation error. When the tooth surface distance $X \geq 0$, the tooth surface has no contact and the collision force is zero. When the tooth surface distance $X<0$, the tooth surface comes into contact, and the collision force is related to the stiffness coefficient $K$, the stiffness force index e, the damping $C$, and the maximum penetration depth $d$. The formula is as follows [1]:

$$
f=K x^{e}+F s(x, 0,0, d, C) x, x<0
$$

It can be seen from the formula that the magnitude of the collision force depends on the following parameters: the stiffness coefficient $K$, the stiffness force index $e$, the damping coefficient $C$, the maximum penetration depth $d$, and the step function $F s$. The stiffness coefficient $K$ is caused by the impacting object's material properties and structural shape decisions [2].

$$
\begin{gathered}
K=\frac{4}{3} R^{\frac{1}{2}} E \\
R=\frac{R_{1} R_{2}}{R_{1}+R_{2}} \\
\frac{1}{E^{*}}=\frac{1-\mu_{1}^{2}}{E_{1}}+\frac{1-\mu_{2}^{2}}{E_{2}}
\end{gathered}
$$

Where $R_{1}$ and $R_{2}$ are the equivalent radii of the two gear contact points, $E_{1}$ and $E_{2}$ are the moduli of elasticity of the two gear materials, and $\mu_{1}$ and $\mu_{2}$ are the Poisson's ratios of the two gear materials.

The step function $F s$ is defined as follows [3]:

$$
F_{S}\left(x, x_{0}, h_{0}, x_{1}, h_{1}\right)=\left\{\begin{array}{c}
h_{0}, x \leq x_{0} \\
h_{0}+a(3-2 \Delta) \Delta^{2}, x_{0}<x<x_{1} \\
h_{1}, x>x_{1}
\end{array}\right.
$$

Where $a=h_{1}-h_{0}, \Delta=\frac{X-X_{0}}{X_{1}-X_{0}}, x$ is an independent variable, $X_{0}$ and $h_{0}$ are initial values, and $X_{1}$ and $h_{1}$ are function values after the end of the function operation.

Considering that the collision force of the gear can be transformed into the impact problem of two radius-changing radius cylinders and gear meshing deformation mainly occurs in the contact area of the gear, the two rotating body contact points, which can be contacted by Hertz collision theory, can be obtained. The formula for calculating the distance is as follows [4]:

$$
x=\left(\frac{9 P^{2}}{16 R E^{2}}\right)^{1 / 3}
$$

Where $P$ is the load applied to the object.

In order to compare with the calculation results of the spur gear, the other three sets of reducer drive system models with different helix angle parameters are established. The helix angles are $8^{\circ}, 12^{\circ}$, and $16^{\circ}$, respectively. 
The main drive system uses a soft-toothed gear, the elastic model of each component is $E=2.09 e+5 \mathrm{~Pa}$, the Poisson's ratio is $v=0.269$, the density is $\rho=7.83 \mathrm{~g} / \mathrm{cm}^{3}$, and the tooth has an excessive fillet radius of $2 \mathrm{~mm}$. Combining the parameters and formulas in the above table, the high-speed stiffness coefficient is $10.48 e+5 \mathrm{~N} / \mathrm{mm}$, and the low-speed stiffness coefficient is $12.37 e+5 \mathrm{~N} / \mathrm{mm}$. The collision index is 2.2 , the damping coefficient is $50 \mathrm{~N} \cdot \mathrm{S} / \mathrm{mm}$, and the penetration depth is $0.1 \mathrm{~mm}$. In the actual work, the lubrication process is required in the gear transmission process, so the friction coefficient is 0.05 and the static friction coefficient is 0.08 [5].

Considering the weight and moment of inertia of each component fully and ignoring the bearing constraint [6], the contact collision model between the tooth surfaces of the gear teeth is established, and the motion pairs of the other components are connected as shown in Table 2.

Table 2. Motion pair connection of the main drive system

\begin{tabular}{|c|c|c|c|}
\hline Driven shaft and ground & Intermediate shaft and ground & Drive shaft and ground & Gears and shafts \\
\hline Rotating pair & Rotating pair & Rotating pair & Fixed pair \\
\hline
\end{tabular}

On the basis of the design calculation, the input shaft speed is the driving, the output load is the working resistance, and the dynamic calculation model of the main transmission system of the track conveyor reduction device is shown in Figure 1.

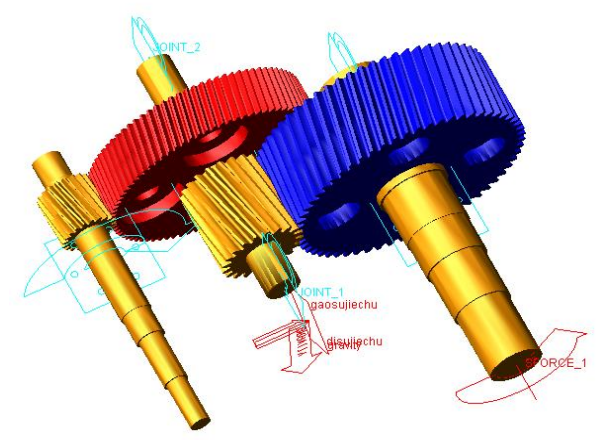

Figure 1. Dynamic calculation model of main drive system

\subsection{Dynamic Calculation Results and Analysis}

The input shaft drive speed is $480 \mathrm{r} / \mathrm{min}$, and the output shaft load is $8.4 e+5 \mathrm{~N} / \mathrm{mm}$. The calculation time of a motion cycle is $0.2 \mathrm{~s}$, and the calculation step is 1,000 steps. Figures 2 to 5 show the dynamic calculation results of the intermediate shaft and output shaft speed of the main drive system at different helix angles.

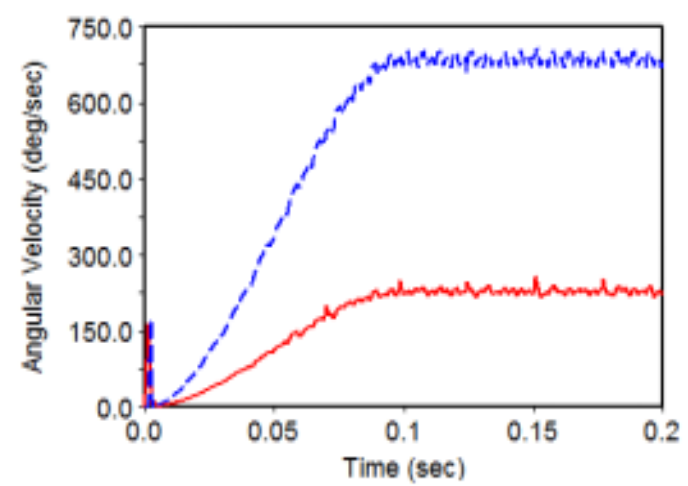

Figure 2. Speed of the intermediate and output shafts at $\beta=0^{\circ}$

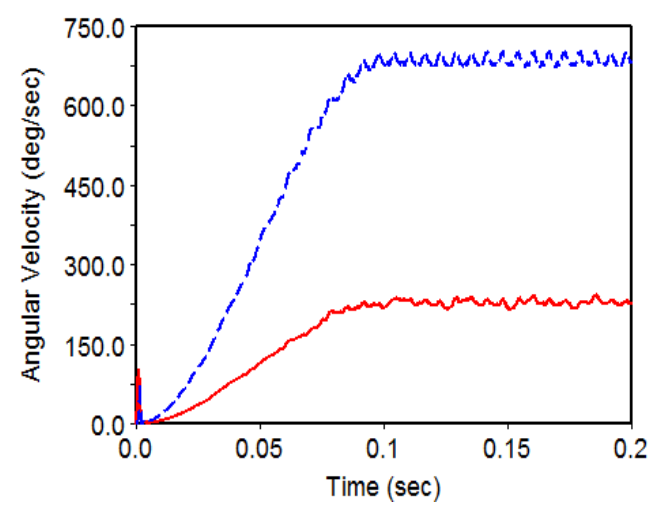

Figure 3. Speed of the intermediate and output shafts at $\beta=8^{\circ}$

From Figures 2 to 5, the rotational speed of each stage of the shaft increases with the increase in the engine speed in 0-0.1 seconds. The angular velocity fluctuates due to the initial meshing collision of the gear in the initial stage of the engine operation, and then it tends to grow steadily. After 0.1 seconds, the rotational speed of the shafts gradually stabilizes, and the reducer begins to run smoothly. 


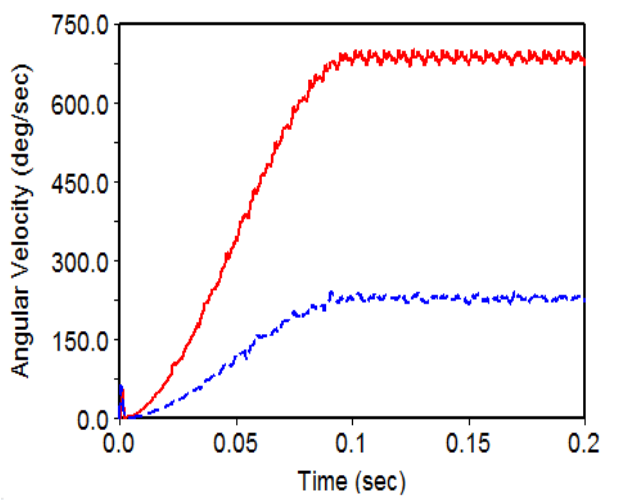

Figure 4. Speed of the intermediate and output shafts at $\beta=12^{\circ}$

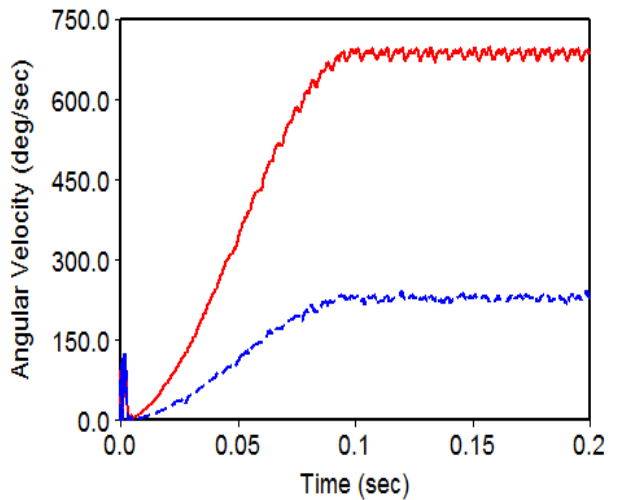

Figure 5. Speed of the intermediate and output shafts at $\beta=16^{\circ}$

In the main drive system, the average speeds of the intermediate shaft and output shaft are shown in Table 3.

Table 3. Dynamic calculation results of the average rotational speed of the intermediate shaft and output shaft of each reducer
\begin{tabular}{|c|c|c|}
\hline & Middle shaft & Output shaft \\
\hline Spur gear & 685.71 & 228.55 \\
\hline$\beta=8^{\circ}$ helical gear & 685.53 & 228.82 \\
\hline$\beta=12^{\circ}$ helical gear & 685.61 & 228.68 \\
\hline$\beta=16^{\circ}$ helical gear & 685.69 & 228.56 \\
\hline
\end{tabular}

As can be seen from the above diagram and table, the rotational speed of the four groups of the reducer fluctuates near its average value. Due to the vibration and collision of the gears in the rotation process, there is a certain error with the theoretical calculation value, but it meets the design requirements [7-8].

Figures 6 to 9 show the dynamic calculation results of the contact force of the tooth surface in the first-level gear transmission during a motion cycle.

The theoretical calculation of the contact force of the first-stage gear transmission tooth surface involves the following formulas:

$$
\begin{gathered}
F_{n}=\frac{F_{t}}{\cos \alpha_{n} \cos \beta} \\
T=9550 \frac{P}{n} \\
F_{t}=\frac{2 T}{d}
\end{gathered}
$$

Where $P$ is the input power, $n$ is the speed, $T$ is the torque, $d$ is the index circle diameter of each gear, $\alpha_{n}$ is the normal pressure angle, and $\beta$ is the helix angle.

In the main transmission system of the deceleration device of the track conveyor, the theoretical and dynamic calculations of the contact force on the tooth surface of the first stage gear transmission under different spiral angles are compared, as shown in Table 4.

According to Figures 6 to 9 and Table 4, in the dynamic calculation, the weight of each component, the moment of inertia, the friction, and the over-rounded corners of the gear teeth are fully considered, and the simulation results are larger than the theoretical calculation values. The error between the simulation results of Table 4 and the theoretical values is obtained by calculation.

(1) Under the comparison of the spur gear and the helical gear with $\beta=8^{\circ}$, the frequency of the vibration shock generated by the helical gear during the rotation is smaller than that of the spur gear. The impact force of the helical gear at 
the initial moment of operation is much smaller than that of the spur gear.

(2) As can be seen from Figures 6 to 8, the larger the helix angle, the larger the degree of coincidence and the smaller the collision force generated by the gear transmission process. Therefore, the actual gear ratio value is not much different from the theoretical calculation value.

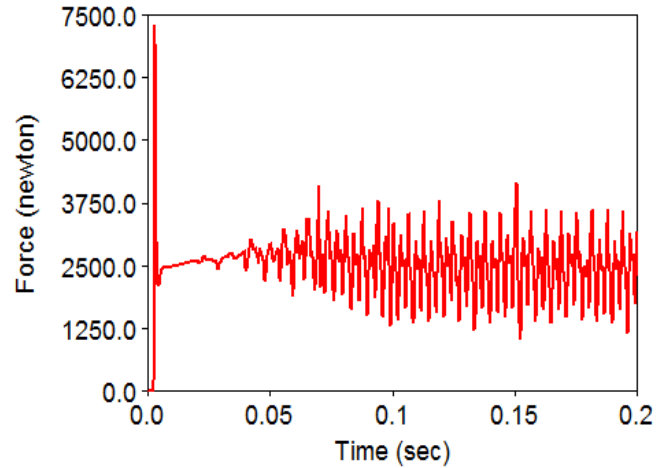

Figure 6. Contact force on tooth surface when $\beta=0^{\circ}$

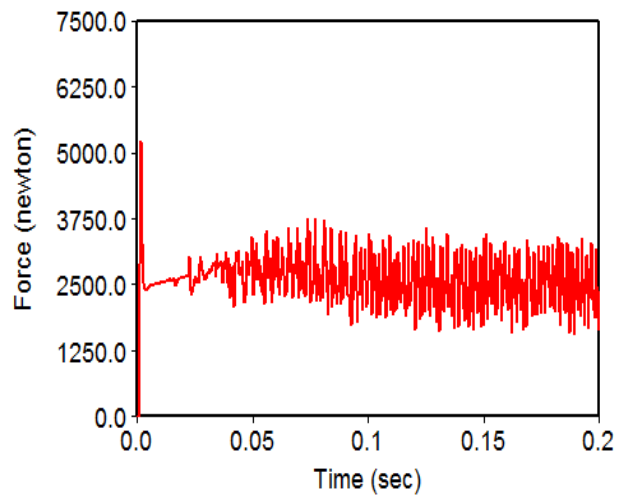

Figure 8. Contact force on tooth surface when $\beta=12^{\circ}$

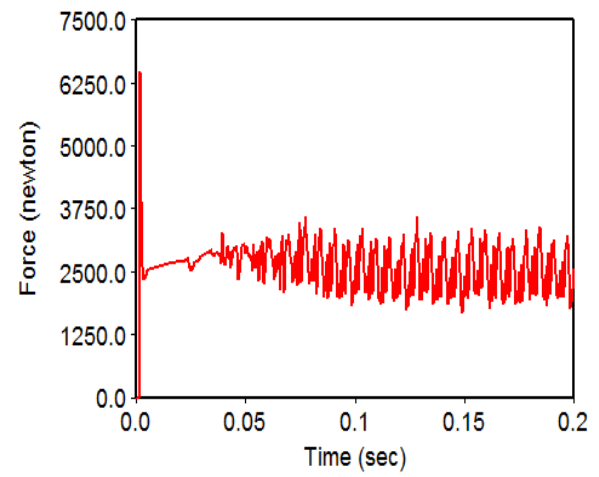

Figure 7. Contact force on tooth surface when $\beta=8^{\circ}$

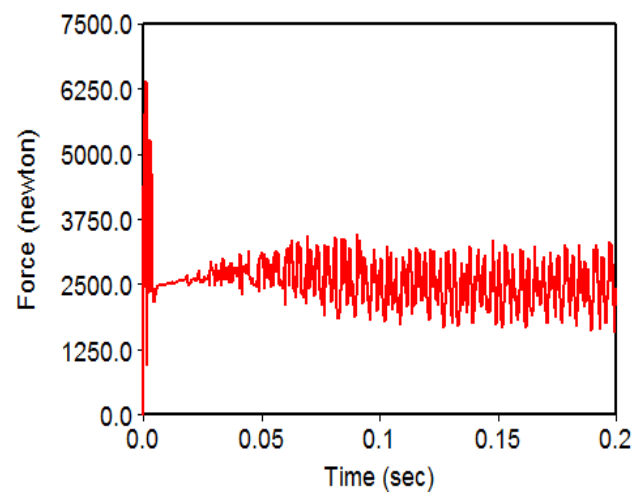

Figure 9. Contact force on tooth surface when $\beta=16^{\circ}$

Table 4. Comparison of theoretical and kinetic calculation results of tooth contact force

\begin{tabular}{|c|c|c|c|c|}
\hline & $\beta=0^{\circ}$ & $\beta=8^{\circ}$ & $\beta=12^{\circ}$ & $\beta=16^{\circ}$ \\
\hline Theoretical calculation result/N & 2480.09 & 2458.52 & 2406.95 & 2362.91 \\
\hline Dynamic calculation results/N & 2636.34 & 2596.22 & 2582.66 & 2580.30 \\
\hline Error & $6.3 \%$ & $5.6 \%$ & $7.3 \%$ & $9.2 \%$ \\
\hline
\end{tabular}

\section{Finite Element Calculation of the Main Drive System}

\subsection{Finite Element Calculation Model}

The finite element calculation grid uses the hexahedral structural unit of the hex dominant method to establish a bonded contact model at the tooth contact position. The friction between the gear tooth faces follows Coulomb's law [9-11], and the partial mesh of the tooth surface contact area is refined. The finite element model is divided into 13,748 mesh units and 55,537 nodes. The dynamic calculation speed and output load are used as load boundaries, and the transient finite element calculation load step is $0.01 \mathrm{~s}$. In the main drive system of the track conveyor deceleration device, the finite element calculation model of the first stage gear transmission friction contact is shown in Figure 10.

The frictional contact problem is a complex nonlinear problem. In the ANSYS Workbench software, the main algorithms for analyzing nonlinear problems are the penalty function, the Lagrangian multiplier algorithm, and the augmented Lagrangian multiplier. The penalty function needs to artificially add a penalty factor, but the size of the penalty factor has a greater impact on the calculation result. The Lagrangian multiplier method increases the scale of the solution due to the introduction of the multiplier and must take appropriate measures to suppress the occurrence of zero principals in the matrix. The augmented Lagrangian method is a combination of the first two methods. It absorbs the advantages of the penalty function method and the Lagrangian method without increasing the solution scale of the system, and the convergence speed is faster. Therefore, this paper adopts the augmented Lagrangian multiplier method [12-15]. 


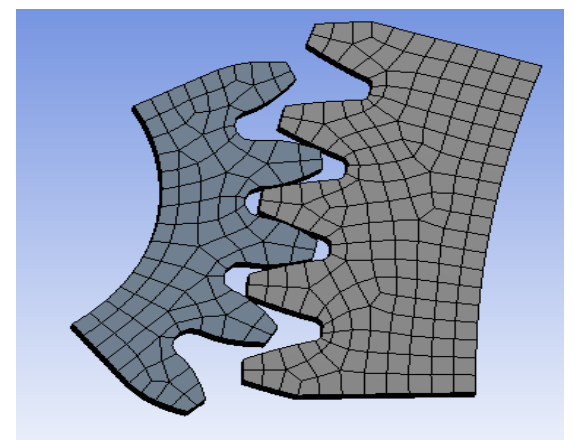

Figure 10. Cut gear model

\subsection{Finite Element Calculation Results and Analysis}

Figures 11 to 14 show the finite element calculation results of the tooth surface contact stress during the first stage gear transmission in the main drive system of the track conveyor deceleration device under different helix angles.

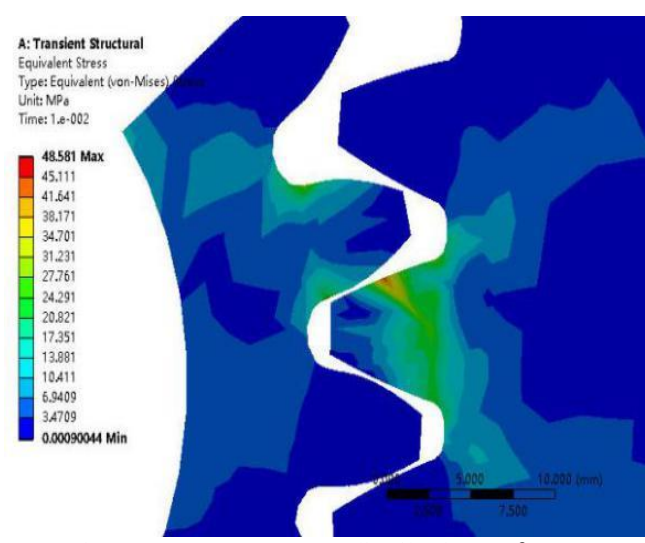

Figure 11. Contact stress distribution at $\beta=0^{\circ}$

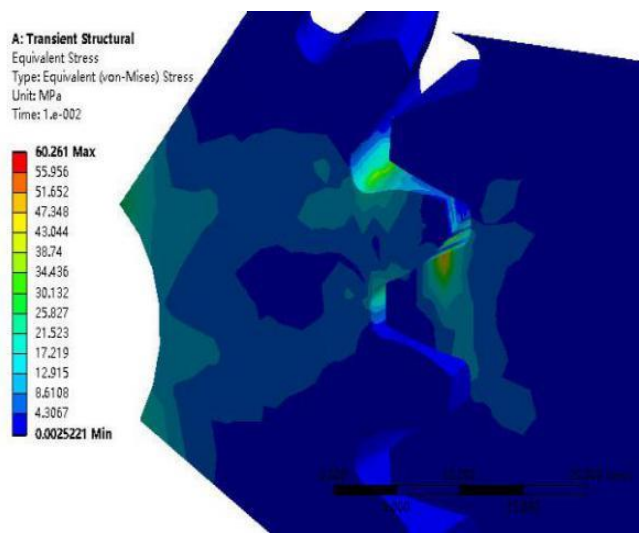

Figure 13. Contact stress distribution at $\beta=12^{\circ}$

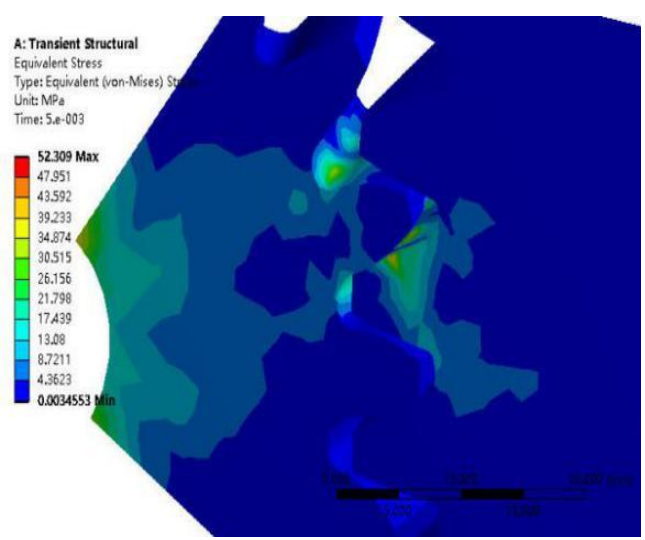

Figure 12. Contact stress distribution at $\beta=8^{\circ}$

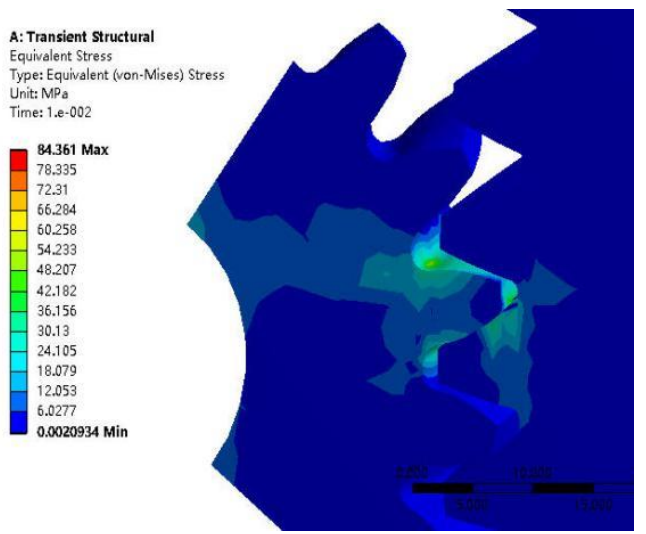

Figure 14. Contact stress distribution at $\beta=16^{\circ}$

The involute gear tooth surface is a relatively complicated curved surface, and since the contact area of the two gears is relatively small, the contact stress is large even if the gear carries a light load. For the convenience of calculation, the involute gear contact can be equivalent to two elastic cylinder contacts, and the Hertz contact pressure formula can be used to approximate the theoretical value of the gear contact stress.

The helical gear contact stress is calculated as follows [16]:

$$
\sigma_{H}=\sqrt{\frac{2 K_{H} T_{1}}{b d_{1}^{2}} \times \frac{u+1}{u}} Z_{H} Z_{E} Z_{\varepsilon} Z_{\beta}
$$


Where $b$ is the tooth width, $d_{1}$ is the gear diameter, $T$ is the torque received by the gear, $K_{H}$ is the load factor calculated by the contact fatigue strength, $K_{H}=K_{A} K_{V} K_{H \alpha} K_{H \beta}, Z_{H}$ is the area coefficient, $Z_{\varepsilon}$ is the coincidence coefficient calculated for contact fatigue strength, $Z_{\beta}$ is the helix angle coefficient calculated for contact fatigue strength, and $Z_{E}$ is the coefficient of elasticity.

According to the table, $Z_{E}, Z_{H}$, and $K_{H}$ were found to be $2.37,188$, and 2.47 , respectively. The calculated coincidence coefficient of $Z_{\varepsilon}$ is 0.879 , and the $Z_{\beta}$ helix angle coefficient is 0.969 .

In the main transmission system of the deceleration device of the track conveyor, the theoretical calculation of the contact stress on the tooth surface of the first stage gear transmission under different spiral angles is compared with the extreme value of the results calculated by the finite element method, as shown in Table 5.

\begin{tabular}{|c|c|c|c|c|}
\hline & $\beta=0^{\circ}$ & $\beta=8^{\circ}$ & $\beta=12^{\circ}$ & $\beta=16^{\circ}$ \\
\hline Theoretical calculation result $(\mathrm{MPa})$ & 130.65 & 128.75 & 126.39 & 123.14 \\
\hline Finite element calculation results (MPa) & 48.581 & 52.309 & 60.261 & 84.361 \\
\hline
\end{tabular}

The results are as follows:

(1) It can be seen from the distribution of tooth profile that the contact stress distribution of spur gear is distributed along the gear axis at the same time, the stress of the whole tooth profile is uniform, and the stress of gear cross-section sudden change is concentrated. The stress is concentrated on a pair of meshing contact gears simultaneously. The stress of helical gears is distributed on two pairs of meshing gears at the same time, which is because the profile of helical gears is gradually entered in the meshing process and gradually disengaged from the meshing process. While one pair of gears is not completely disengaged, another pair of adjacent gears has entered the meshing state.

(2) It can be seen that the stress distribution area of the spur gear is wider than that of the bevel gear, and the stress area of the bevel gear increases gradually as the spiral angle increases. This is due to the fact that more helical gears are engaged at the same time than straight gears, and more stress surfaces reduce the stress distribution of the whole gear.

(3) Taking the dynamic calculation result as the load boundary of the finite element calculation, the weight of each component, the moment of inertia, the friction, and the over-rounded fillet of the gear tooth are fully considered. The stress extremum of Table 5 and the cloud image can be obtained. The maximum value of stress increases as the spiral angle increases. This is because changes in the meshing line in the meshing process of the helical gear will lead to the local stress value of the tooth profile. The maximum value of the results of finite element calculation is within the range of theoretical calculation strength.

\section{Fatigue Damage Reliability Calculation}

In order to obtain the influence of different helix angles on the gear fatigue damage and avoid the contact fatigue failure of the tooth surface during the working process, based on the finite element calculation results of the contact stress, the different helix angles are respectively carried out using NcodeDesignlife software. Because the stress is high and the strain is low, the gear failure type belongs to high cycle fatigue, so the $S-N$ curve is used to analyze the fatigue. The $S$ - $N$ curve of the material refers to the standard specimen made of the raw material in the shape of a circular rod, under the specified processing precision grade and heat treatment process, and the fatigue life under the actions of tension, compression, bending, and torsion can be obtained. Thus, the corresponding $S-N$ curve is obtained. Therefore, because different parts vary in shape, machining precision, and heat treatment processes, their $S$ - $N$ curves are naturally different. In this paper, according to the yield strength, tensile strength, elastic modulus, and other parameters of the material, the theoretical $S$ - $N$ curve of the material is obtained (as shown in Figure 15), and the Goodman method is modified in nCode [17].

The calculation uses the miner linear cumulative damage theory. When the material withstands the stress higher than the fatigue limit, each cycle in the operation will cause certain damage to the corresponding materials. The fatigue damage caused by different stresses can be regarded as independent. The average damage caused by each cycle is $1 / N$. This damage can be accumulated, and the damage caused by $n$ constant amplitude loads is $n / N$. The damage $D$ of the variable amplitude load is equal to the sum of the cycle ratios, i.e., 1 is the stress level series of the variable amplitude load, $n_{i}$ is the number of 
cycles of the $i^{\text {th }}$ load, and $N_{i}$ is the fatigue life under the $i^{\text {th }}$ load. When the damage accumulates to the critical value $D_{f}$, fatigue occurs.

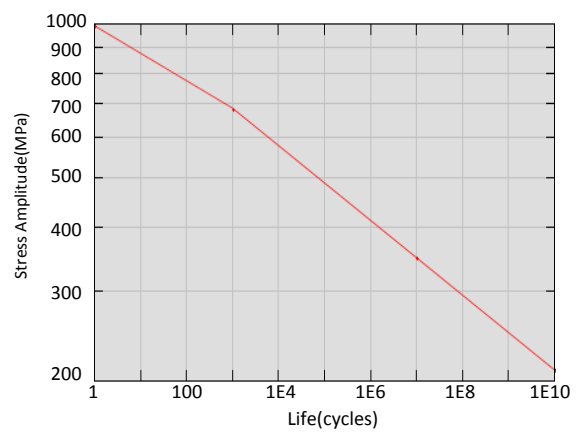

Figure 15. S-N curve

The labor is ruined, where $D_{f}$ is the critical damage and referred to as damage [18].

The finite element calculation results of the fatigue damage degree of the gear transmission at different helix angles are shown in Figures 16 to 19.

As can be seen from Figures 16 to 19, both the driving wheel and the driven wheel are subjected to fatigue damage, and the maximum fatigue damage is located at the gear contact surface and the root of the tooth. Under the same load conditions, the maximum fatigue damage value of the spur gear is $9.449 \mathrm{e}-10$, the maximum fatigue damage value of the $\beta=8^{\circ}$ helical gear is $8.295 \mathrm{e}-10$, and the maximum fatigue damage value of the $\beta=12^{\circ}$ helical gear is 5.712e. The maximum fatigue damage value of the $-10, \beta=16^{\circ}$ helical gear is $8.616 \mathrm{e}-11$. Therefore, it can be seen that under the condition of constant load and other variable factors, the fatigue damage value decreases as the gear helix angle increases.
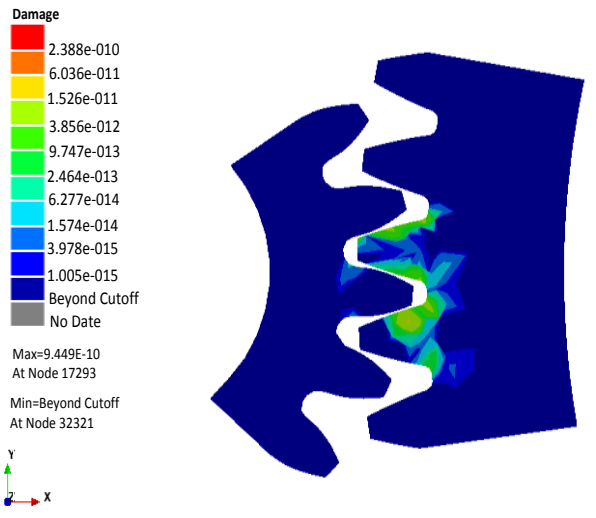

Figure 16. $\beta=0^{\circ}$ gear transmission fatigue damage distribution
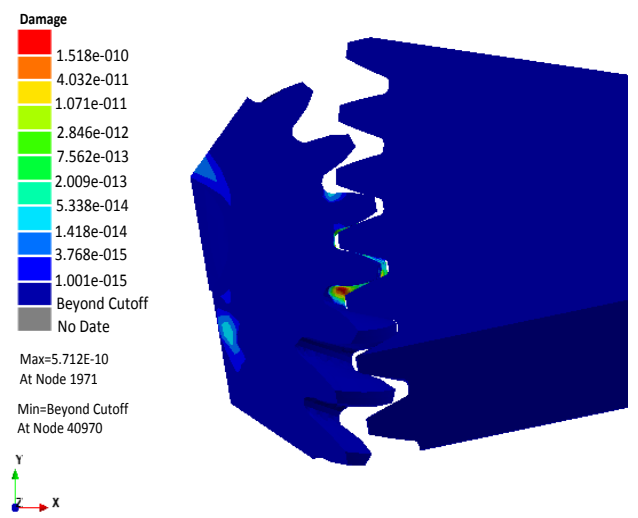

Figure 18. $\beta=12^{\circ}$ gear transmission fatigue damage distribution
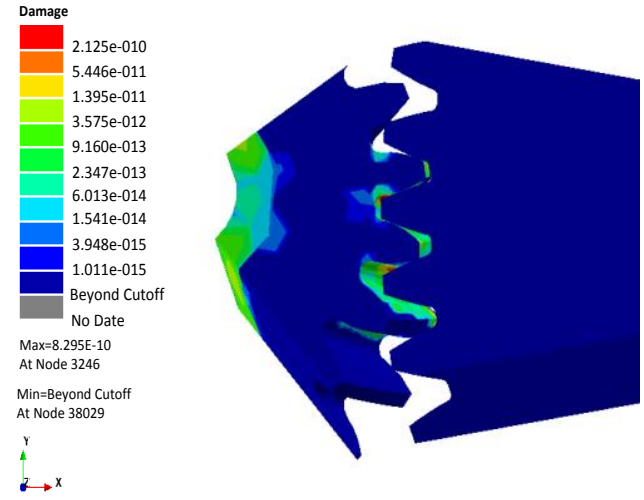

Figure 17. $\beta=8^{\circ}$ gear transmission fatigue damage distribution
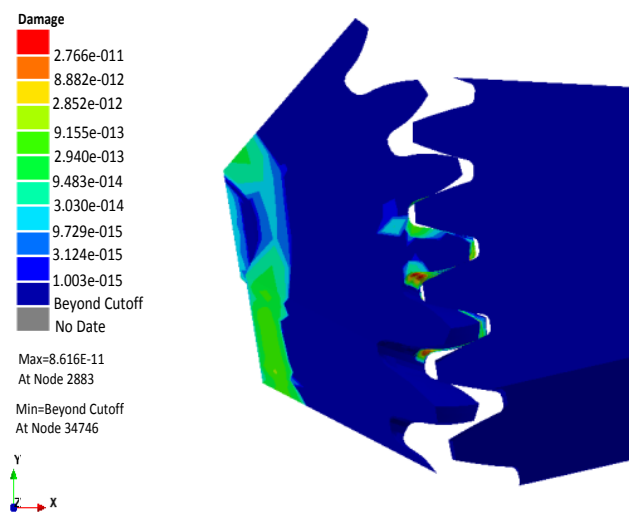

Figure 19. $\beta=16^{\circ}$ gear transmission fatigue damage distribution 


\section{Conclusions}

(1) The larger the helix angle, the smaller the collision contact force between the gears and the higher the transmission efficiency. However, as the helix angle increases, the axial force of the gear will also increase. In the pursuit of low noise during the transmission process and stable transmission, the bearing capacity of the shaft and the bearing should be fully considered. The ADAMS dynamics analysis results are consistent with the actual trend and are not much different from the theoretical calculations.

(2) The force receiving surface of the spur gear during the meshing process is constant, and the contact stress is uniformly distributed on the contact surface. The helical gear changes at any time during the meshing process due to the contact surface area, and there is a stress concentration point on the tooth profile of the helical gear. The simulated calculation strength is within the range of theoretical calculations.

(3) The fatigue damage analysis of spur gears and helical gears under constant load conditions shows the influence of the helix angle on gear life and fatigue damage. It provides a reference for the selection of gears in practical situations.

\section{Acknowledgements}

This work is supported by the Key Scientific Research Project of the Inner Mongolia Autonomous Region University (No. NJZZ18075), the Natural Science Fund of the Inner Mongolia Autonomous Region (No. 2018MS05060), and the Talent Development Fund of the Inner Mongolia Autonomous Region.

\section{References}

1. Y. N. Wang, Z. G. Zhang, and Y. Z. Lin, "Display Dynamics Simulation Research on Integrated Structure System of Multistage Cylindrical Gear Reducer," Mechanics and Electronics, Vol. 36, No. 6, pp. 13-16, 2018

2. L. Zhang, "Analysis of Abnormal Vibration Characteristics of Gear Reducer," Journal of Huaibei Vocational and Technical College, Vol. 17, No. 3, pp. 104-106, 2018

3. J. Y. Li, Z. J. Gou, and Y. Li, "Dynamic Simulation of Gear Meshing Process based on ADAMS," Design and Research, pp. $15-18,2018$

4. Y. Huang, "Application of Cumulative Impulse Detection Algorithms for Gearbox in Wind Generator," Shanghai Electric Technology, pp. 18-22, 2018

5. Z. H. Huang, X. J. Zhang, and Y. J. Zhou, "Meshing Impact Force Simulation of Involute Gears," Journal of Zhongnan University, pp. 379-383, 2011

6. A. M. Liu, Y. Z. Han, and L. Q. Wang, "Dynamic Simulation of Gear Reducer based on Pro/E and ADAMS," Coal Mine Machinery, pp. 47-49, 2011

7. Y. M. Mou, Z. D. Fang, and X. J. Zhang, "Design and Analysis of High-Order Transmission Error of High Coincidence Arc Gear," Journal of Huazhong University of Science and Technology, Vol. 46, No. 7, pp. 67-72, 2018

8. L. H. Chang, G. Liu, and Z. X. He, "Study on the Variation Law of Static Transmission Error of Cylindrical Gear Pair," Mechanical Transmission, Vol. 41, No. 7, pp. 2-11+21, 2017

9. Z. H. Fan, X. Y. Zhao, and H. W. Yan, "Contact finite Element Analysis of Helical Gears based on ANSYS," Mechanical Transmission, pp. 68-70, 2010

10. H. P. Li, L. M. Wang, G. Chen, and Y. Dong, "Dynamic Meshing Characteristics Analysis of Differential Gears based on Finite Element Method," Journal of Jiangsu University, Vol. 38, No. 6, pp. 627-631, 2017

11. L. Y. Wei, C. L. Wang, L. Y. Zhang, X. M. Liu, X. T. Qiao, and R. F. Wang, "Finite Element Analysis of Meshing Stiffness of Harmonic Gears," Mechanical Transmission, Vol. 42, No. 6, pp. 144-150, 2018

12. W. Liu, J. B. Cai, C. B. Ding, and X. W. Wang, "Contact Stress Analysis and Profile Modification of High Frequency Crusher Gears," Modular Machine Tools and Automatic Processing Technology, pp. 60-64, 2017

13. B. He, S. Huang, and X. L. He, "Numerical Simulation of Gear Surface Hardening using the Finite Element Method," The International Journal of Advanced Manufacturing Technology, Vol. 74, No. 5-8, pp. 665-672, 2014

14. S. S. Patil, S. Karuppanan, I. Atanasovska, and A. A. Wahab, "Contact Stress Analysis of Helical Gear Pairs, Including Frictional Coefficients," International Journal of Mechanical Sciences, pp. 205-211, 2014

15. M. Behzad, M. Alvandi, D. Mba, and J. Jamali, "A Finite Element-based Algorithm for Rubbing Induced Vibration Prediction in Rotors," Journal of Sound and Vibration, Vol. 332, No. 21, pp. 5523-5542, 2013

16. L. G. Pu and G. D. Chen, "Mechanical Design," Higher Education Press, Beijing, 2013

17. Y. F. Gong and F. Jia, "Fatigue Reliability of a Steel Structure Crane Beam based on nCode Design-Life," Liaoning University of Engineering and Technology, Vol. 37, No. 2, pp. 371-375, 2018

18. K. Tian, P. Wang, X. Q. Han, W. Q. Qin, and W. Liang, "Reliability Analysis of Subsynchronous Oscillation of Power System on Fatigue Damage of Wind Turbine Shaft System," Acta Energia Sinica, Vol. 38, No. 3, pp. 586-592, 2017 